\title{
More refined typology and design in linguistic relativity
}

\section{The case of motion event encoding}

\author{
Pablo Bernabeu ${ }^{1,2,3}$ and Richard Tillman 4 \\ ${ }^{1}$ Radboud University $\mid{ }^{2}$ Tilburg University $\mid{ }^{3}$ Lancaster University \\ ${ }^{4}$ University of Cincinnati
}

Linguistic relativity is the influence of language on other realms of cognition. For instance, the way movement is expressed in a person's native language may influence how they perceive movement. Motion event encoding (MEE) is usually framed as a typological dichotomy. Path-in-verb languages tend to encode path information within the verb (e.g., 'leave'), whereas manner-in-verb languages encode manner (e.g., 'jump'). The results of MEEbased linguistic relativity experiments range from no effect to effects on verbal and nonverbal cognition. Seeking a more definitive conclusion, we propose linguistic and experimental enhancements. First, we examine stateof-the-art typology, suggesting how a recent MEE classification across twenty languages (Verkerk, 2014) may enable more powerful analyses. Second, we review procedural challenges such as the influence of verbal thought and second-guessing in experiments. To tackle these challenges, we propose distinguishing verbal and nonverbal subgroups, and having enough filler items. Finally we exemplify this in an experimental design.

Keywords: linguistic relativity, Sapir-Whorf hypothesis, lexicalization patterns, motion event encoding, motion language, cognitive semantics, language typology, linguistics, psycholinguistics, methods

\section{Introduction}

Linguistic relativity refers to the influence of language on perception and behaviour (Sapir, 1921). Research has suggested that standard forms of expression in language may influence cognitive processes beyond language itself, such as attention to and recall of events (Gumperz \& Levinson, 1996). The current paper addresses potential linguistic relativity effects based on how languages express 
motion (Skordos \& Papafragou, 2014). We review methodological challenges and provide some suggestions.

\section{Motion event encoding}

In a given language, the way motion events are conveyed is linked to how much content is portrayed by verbs in sentences. In satellite-framed languages (e.g., Germanic and Balto-Slavic families), content is often distributed beyond the verb by adjuncts. By contrast, in verb-framed languages (e.g., Greek and the Romance family), verbs do not tend to be aided or modified by many adjuncts (Slobin, 1996). This typological distinction maps onto the grammar of motion events.

Satellite-framed languages tend to encode manner information within the verb, a pattern known as manner-in-verb (e.g., verbs 'slide', 'tiptoe'). Conversely, verb-framed languages are path-in-verb, as they tend to place directional information within the verb (e.g., verbs 'leave', 'cross'). Path-in-verb languages often place manner information in non-finite clauses (e.g., 'by sliding'), or omit it altogether. This long-standing, two-way classification, initiated by Talmy (1991), has been qualified in recent years.

Slobin (1996) noted that manner-in-verb languages often richly encode path information by means of verbal adjuncts. Less often, the reverse happens too: path-in-verb languages featuring manner verbs (Naigles, Eisenberg, Kako, Highter, \& McGraw, 1998). Having noticed these nuances, scholars moved away from the path/manner dichotomy to consider these differences as a continuum. Slobin (2006) thus noted the importance of acknowledging these nuances when designing linguistic relativity experiments. Indeed, Bohnemeyer, Eisenbeiss, and Narasimhan (2006) found that the same stimuli and tasks could yield fundamentally different results depending on which language was studied in each typological group.

A comprehensive, new approach to Motion Event Encoding (MEE) was developed by Verkerk (2014). Verkerk examined sentence constructions used for MEE. These spanned from the more general characteristics of a grammar - satelliteframing, verb-framing, subordination, coordination, deictic verb, deictic verbframed - to others that were specific to MEE - path-only, manner-only, mannerplus-path verb. The author standardized the occurrence of those constructions in many texts in each language.

Verkerk found large correlations among the variables, which was natural considering the similarity among the lexicalization patterns measured. The variables were examined by running a Principal Component Analysis. The analysis returned two significant principal components (PC). The first PC (verb/satellite-framed) 
explained from $79 \%$ to $85 \%$ of the variance from the nine original variables (the two percentages correspond to different data sets), and the second PC (deictic construction) explained from $6.8 \%$ to $9.8 \%$ of the variance. The author further states that some languages - e.g., Polish, Lithuanian - rely more on satellite framing, while others - e.g., Hindi, Nepali - use it much less. Verkerk's research was highly sophisticated in capturing MEE patterns as numeric continuums, and encompassing grammatical constructions beyond Path and Manner alone.

\section{Linguistic relativity}

Since its introduction by Sapir (1921), the linguistic relativity hypothesis has taken various forms. Some experiments supported relativism (e.g., Lucy, 1992), while some suggested no effects (Papafragou, Massey, \& Gleitman, 2002), and yet others concluded, for instance, that the influence of language on thought may be limited to language-mediated thought processes (Trueswell \& Papafragou, 2010; Slobin, 1987).

Boroditsky (2001) addressed some possible experimental shortcomings. First, the use of the native language of participants in experiments may limit the research scope to language-mediated thought, hence constraining the possible conclusions. At the same time, nonetheless, the author noted the challenges of alternatives such as using second languages. One alternative approach is language interference (Trueswell \& Papafragou, 2010), whilst another is nonverbal tasks (Montero-Melis et al., 2017). Boroditsky also contended that the motion events in experiments should be presented in actual video rather than as consecutive pictures.

In order to protect the experimental manipulation, tasks should prevent participants from second-guessing the research question. For this purpose, MonteroMelis et al. (2017) has suggested the use of tasks that do not explicitly contrast the Path and Manner categories.

\section{A novel experimental approach}

The literature suggests that MEE-based linguistic relativity experiments may be improved in two main areas: selection of languages and experimental design. Recent advancements in MEE typology may enable us to select the languages based on a multivariate, continuum-based classification, such as Verkerk (2014). Hereby we propose methodology that will (1) establish whether participants engage in verbal or nonverbal thought during the task - which is central to the 
nature of linguistic relativity -, and (2) prevent participants from noticing the focus on motion (Montero-Melis et al., 2017).

\subsection{Methods}

Participants will watch short video scenes featuring a character in motion, and then two tasks will be used to measure the attention paid to Path and Manner (alongside non-motion filler categories such as Music). Response Time (RT) and category choice will be measured.

\subsubsection{Participants}

The two language groups are formed by native speakers of languages studied in Verkerk (2014). Verkerk provided rankings for each language on several MEErelated variables. The best suited variable for the current purpose is Verkerk's first PC (verb- vs. satellite-framing), which accounts for at least $80 \%$ of the variance in MEE variables within twenty Indo-European languages. The languages chosen should preferably be well apart on the PC; for instance, Albanian on the verbframed end, and Swedish on the satellite-framed end (see Section 2 above; in Verkerk, 2014, see Figures 2.2 and 2.3).

Each language group in turn contains two subgroups of participants. The Verbal subgroup has words in the experiment, whereas the Nonverbal subgroup has pictures instead. These groups will be analysed relative to each other. This relative approach allows us to regard the Nonverbal group as a less verbal group in practice, which is important because language is very widespread in human thought (Trueswell \& Papafragou, 2010).

\subsubsection{Materials}

Each trial commences with a scene presenting characteristics in manner and path of motion, colour of clothes, setting, and music. For instance, a character might be identified as crawling towards the left, wearing blue clothes, in a garden, while jazz music is playing. The scenes may be real-life videos or virtual animations.

After the video, a set of options appears (see Table 1 and Figure 1), first within one single category (e.g., Path), then within two (e.g., Setting and Action). The Path and Manner of motion of the scenes may likely afford several answers (e.g., left and out as the Path). Although path-in-verb languages do not naturally use manner verbs often (Slobin, 2006), we do not think these verbs would have a huge impact to the path-in-verb language group, because a small number of these verbs are present. 
Table 1. The five categories with their features in the verbal format. The category titled 'Action' is indeed manner of motion

\begin{tabular}{lllll}
\hline Action & Path & Clothes & Setting & Music \\
\hline Climb & Down & Black & Bedroom & Classical \\
Crawl & In & Blue & Football field & Disco \\
Jump & Left & Brown & Garage & Jazz \\
Pop & Out & Green & Garden & Reggae \\
Roll & Over & Grey & Gym & Rock \\
Run & Up & Orange & Kitchen & Salsa \\
Skip & Right & Pink & Library & \\
Walk & Through & Red & Living room & \\
& & White & & \\
& & Yellow & & \\
\hline
\end{tabular}

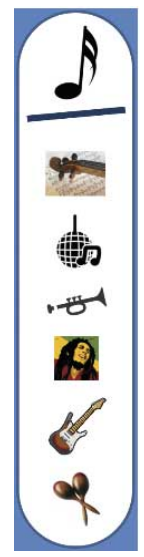

Figure 1. An example of the music category in the nonverbal format

The first two categories are the targets, and the rest are fillers. Their order will be randomized in the experiment. The inclusion of specific Action and Path features (e.g., 'climb', 'down') is to be based on choosing easily accessible concepts. The use of filler categories, outnumbering the target categories, is aimed to reduce the chance of participants figuring out the experimental purpose. 


\subsubsection{Procedure}

On each trial, participants watch a short video scene and complete two recall tasks.

Task 1. One category out of five (e.g., Path) is randomly presented in each trial. Participants select only one feature (e.g., Out), and RT is measured.

Task 2. Two categories (e.g., Music and Action) are randomly presented in each trial. Participants select one feature of only one category. RT and category choice are measured.

An example is provided in Table 2.

Table 2. Example of tasks 1 and 2

\begin{tabular}{lll}
\hline Task 1 & Task 2 & \\
\hline Setting & Action & Clothes \\
Kitchen & Walk & Pink \\
Bedroom & Run & Black \\
Library & Roll & Grey \\
Living room & Skip & Red \\
Garage & Jump & Orange \\
Garden & Climb & Yellow \\
Football field & Crawl & Green \\
Gym & & Brown \\
& & White \\
& & Blue \\
\hline
\end{tabular}

\subsubsection{Analysis and hypotheses}

The general design is a $2 \times 2 \times 2$ (language groups $\times$ Verbal/Nonverbal subgroups $\times$ tasks). The linguistic relativity effect is operationalized as the difference in results between the language groups within each Verbal/Nonverbal subgroup.

The analyses first examine differences between the language groups in terms of the RT dedicated to recalling manner and path of motion in each task, for which a three-way ANOVA (or mixed effects model) is performed. Next, for Task 2 alone, the choice of responding to Path or Manner of motion is analysed by means of a Chi-Square test. 
Previous research affords three broad lines of hypotheses (Boroditsky, 2001; Montero-Melis et al., 2017; Trueswell, \& Papafragou, 2010):

- Strong relativity predicts that the language groups should significantly differ, and that this relativity effect should hold in both Verbal and Nonverbal subgroups. Speakers of manner-in-verb languages (e.g., Dutch), may show a response advantage for manner over path, reflected in the RTs in Tasks 1 and 2. Conversely, the speakers of path-in-verb languages (e.g., French) would have an advantage for path over manner. In Task 2, the RT advantage would be further accompanied by a relative preference for the corresponding category. Since the relativity effect is not limited to language-based thought under this account, the effect would be expected to hold in the Verbal and the Nonverbal subgroups alike.

- Thinking-for-Speaking predicts a relativity effect primarily within the Verbal subgroups, whereas the Nonverbal subgroups would present a milder effect, if any.

- The non-relativistic approach predicts no remarkable differences across language groups for any subgroup. Such a result would thus suggest that the influence of our first language on general thought may be simply too small.

\section{Conclusion}

We reviewed linguistic relativity research that has drawn on motion event encoding (MEE), for which we considered both the typological basis and the experimental procedure. First, we looked at Verkerk's (2014) typology of MEE in twenty Indo-European languages, a quantitative analysis that frames MEE as a continuum consisting of multiple variables besides manner and path. We suggest that this classification could be used to select language groups for experiments in a more robust manner. Turning to the experimental procedure, we reviewed challenges such as preventing participants from second-guessing, and establishing the degree of verbal or nonverbal thought that is involved in a relativity effect. With these things considered, we outline an experimental design that probes into all hypotheses, such as Thinking-for-Speaking, by including verbal and nonverbal subgroups of participants within each language group.

\section{Acknowledgements}

We highly appreciate the advice from Elisabeth Norcliffe, Annemarie Verkerk, Shelli Feist, the editor, and two anonymous reviewers. 


\section{References}

Bohnemeyer, J., Eisenbeiss, S., Narasimhan, B. (2006). Ways to go: Methodological considerations in Whorfian studies in motion events. Colchester: Dept. of Language and Linguistics, University of Essex.

Boroditsky, L. (2001). Does language shape thought? English and Mandarin speakers' conceptions of time. Cognitive Psychology, 43(1), 1-22. https://doi.org/10.1006/cogp.2001.0748

Gumperz, J. J., \& Levinson, S. C. (Eds.). (1996). Rethinking linguistic relativity. Cambridge, UK: Cambridge University Press.

Lucy, J. A. (1992). Language diversity and thought: A reformulation of the linguistic relativity hypothesis. Cambridge, UK: Cambridge University Press. https://doi.org/10.1017/CBO9780511620843

Montero-Melis, G., Eisenbeiss, S., Narasimhan, B., Ibarretxe-Antuñano, I., Kita, S., Kopecka, A., Lüpke, F., Nikitina, T., Tragel, I., Jaeger, T. F., \& Bohnemeyer, J. (2017). Satellite- vs. verb-framing underpredicts nonverbal motion categorization: Insights from a large language sample and simulations. Cognitive Semantics, 3(1), 36-61. https://doi.org/10.1163/23526416-00301002

Naigles, L., Eisenberg, A., Kako, E., Highter, M., \& McGraw, N. (1998). Speaking of motion: Verb use in English and Spanish. Language and Cognitive Processes, 13(5), 521-549. https://doi.org/10.1080/016909698386429

Papafragou, A., Massey, C., \& Gleitman, L. (2002). Shake, rattle, 'n' roll: The representation of motion in thought and language. Cognition, 84(2), 189-219. https://doi.org/10.1016/S0010-0277(02)00046-X

Sapir, E. (1921). Language: An introduction to the study of speech. New York: Harcourt, Brace, and World.

Skordos, D., \& Papafragou, A. (2014). Lexical, syntactic, and semantic-geometric factors in the acquisition of motion predicates. Developmental Psychology, 5o(7), 1985-1998. https://doi.org/10.1037/aoo36970

Slobin, D. I. (1987). Thinking for speaking. Proceedings of the Thirteenth Annual Meeting of the Berkeley Linguistics Society (pp. 435-445). Berkeley University of California.

Slobin, D. I. (1996). Two ways to travel: Verbs of motion in English and Spanish. In M. Shibatani, \& S. A. Thomspon (Eds.), Grammatical constructions: Their form and meaning (pp. 195-219). Oxford, UK: Clarendon Press.

Slobin, D. I. (2006). What makes manner of motion salient? Explorations in linguistic typology, discourse, and cognition. In M. Hickmann, \& S. Robert (Eds.), Space in languages: Linguistic systems and cognitive categories (pp. 59-81).

Amsterdam/Philadelphia: John Benjamins. https://doi.org/10.1075/tsl.66.05slo

Talmy, L. (1991). Path to realization: A typology of event conflation. Proceedings of the Seventeenth Annual Meeting of the Berkeley Linguistics Society (pp. 480-519). Berkeley University of California.

Trueswell, J., \& Papafragou, A. (2010). Perceiving and remembering events cross-linguistically: Evidence from dual-task paradigms. Journal of Memory and Language, 63(1), 64-82. https://doi.org/10.1016/j.jml.2010.02.006

Verkerk, A. (2014). The evolutionary dynamics of motion event encoding. Enschede: Ipskamp Drukkers. https://core.ac.uk/download/pdf/20488979.pdf 


\section{Address for correspondence}

Pablo Bernabeu

D26 Fylde College

Department of Psychology

Lancaster, LA1 4 YW

United Kingdom

pcbernabeu@gmail.com

p.bernabeu@lancaster.ac.uk

iD https://orcid.org/oooo-0oo3-1083-2460

\section{Co-author information}

Richard Tillman

Department of Psychology

University of Cincinnati

richard.n.tillman@gmail.com

\section{Publication history}

Date received: 1 July 2015

Date accepted: 12 September 2018

Published online: 11 April 2019 